\title{
O ensino de Língua Portuguesa na modalidade remota: análise de uma experiência contemporânea
}

\author{
Alessandra Cristina Costa Mendes ${ }^{\mathrm{i}}$
}

\begin{abstract}
RESUMO
O ano de 2020 é um marco na história, sobretudo pelas imposições provocadas pela pandemia de Covid-19. A comunidade acadêmica foi obrigada a repensar o seu fazer pedagógico por conta das medidas de isolamento e distanciamento social que repercutiram numa revisão em relação ao processo de ensino e aprendizagem, tanto por parte dos professores quanto do alunado. Assim, o principal objetivo desta pesquisa envolve a apresentação de conceitos relacionados ao ensino de Língua Portuguesa, às estratégias de ensino na modalidade educação remota e à análise da proposta pedagógica adotada pela Secretaria Municipal de Educação da cidade do Rio de Janeiro. O estudo dialoga com as pesquisas de Mascuschi (2002 e 2010), com ênfase nas questões relativas ao texto. Os resultados versam sobre as expectativas da educação póspandemia principalmente nos conteúdos sobre gêneros textuais, leitura e escrita.
\end{abstract}

Palavras-chave: Gêneros textuais; Ensino de Língua Portuguesa; Leitura e escrita; Ensino Remoto.

\section{RESUMEN}

El año 2020 es un hito en la historia, sobre todo por las imposiciones provocadas por la pandemia Covid-19. La comunidad académica se vio obligada a repensar su práctica pedagógica debido a las medidas de aislamiento y distanciamiento social que se reflejaron en una revisión en relación al proceso de enseñanza y aprendizaje, tanto por parte de docentes como de estudiantes. Así, el objetivo principal de esta investigación pasa por la presentación de conceptos relacionados con la enseñanza del idioma portugués, las estrategias de enseñanza en la modalidad de educación remota y el análisis de la propuesta pedagógica adoptada por Secretaria Municipal de Educação de la ciudad de Río de Janeiro. El estudio dialoga con la investigación de Mascuschi (2002 y 2010), con énfasis en cuestiones relacionadas con el texto. Los resultados abordan las expectativas de la educación pospandémica, principalmente en los contenidos sobre géneros textuales y lectura y escritura.

Palabras clave: Géneros textuales; Enseñanza de la lengua portuguesa; Lectura y escritura; Enseñanza remota.

\footnotetext{
${ }^{\mathrm{i}}$ Mestranda em Língua Portuguesa (UERJ). E-mail: alecrismendes@gmail.com.
} 


\section{INTRODUÇÃO}

Já faz certo tempo que o mundo virtual invadiu o cotidiano das pessoas e se tornou um passaporte para o acesso às múltiplas possibilidades e facilidades de que ele dispõe. A leitura e a escrita desempenham um papel central, uma vez que, sem elas, o universo virtual não passaria de uma propagação de informações limitada à transmissão de dados sonoros e visuais. Desse modo, torna-se essencial o desenvolvimento das habilidades linguísticas voltadas para o uso social da leitura e da escrita de forma que englobe o contexto digital.

Os gêneros textuais são atualizados a todo momento e, por conseguinte, mais habilidades devem ser desenvolvidas pelo aluno de forma que ele possa se inserir na sociedade física e virtual. A sua autonomia diante do texto estabelece sua capacidade de transitar em diferentes esferas textuais e de lidar com situações adversas.

Por isso, esta pesquisa, intitulada "Ensino de Língua Portuguesa na modalidade educação remota: análise de uma experiência contemporânea", tem por objetivo propor reflexões acerca do ensino de Língua Portuguesa durante a pandemia provocada pelo Covid-19 no ano 2020, que provocou uma forçada aliança entre tecnologia e ensino, exigindo a adaptação das práticas pedagógicas de forma a respeitar as medidas de distanciamento social.

Sendo assim, são apresentadas algumas considerações a respeito do ensino de Língua Portuguesa como prática social, uma proposta que coaduna com as pesquisas dos Parâmetros Curriculares Nacionais e da Base Nacional Comum Curricular. Também é apresentada uma análise do material didático produzido pela Secretaria Municipal de Educação da Prefeitura do Rio de Janeiro (SME-RJ), de forma a analisar suas estratégias de ensino-aprendizagem para o ensino remoto.

Alguns questionamentos são pertinentes: os currículos previam o desenvolvimento da habilidade de uso das mídias voltadas para a aquisição do próprio conhecimento? As redes sociais, geralmente voltadas para o lazer e o entretenimento, podem servir de plataforma de ensino a distância? Quais os limites do ensino remoto emergencial, sobretudo na rede pública de ensino?

No intuito de tentar respondê-los, este trabalho está organizado da seguinte forma: (i) apresentação dos princípios norteadores do ensino de Língua Portuguesa 
como prática social com base nos pressupostos teóricos de Luiz Antônio Marcuschi (2002 e 2010); e (ii) breve reflexão sobre a aliança entre tecnologia e educação e análise do material didático produzido pela SME-RJ.

Destarte, pretende-se com o exposto contribuir para as pesquisas que enfocam o ensino de Língua Portuguesa e registrar as expectativas relativas aos rumos da educação a curto, médio e longo prazo após a pandemia.

\section{O ENSINO DE LÍNGUA PORTUGUESA COMO PRÁTICA SOCIAL}

A linguagem é elemento essencial às relações humanas. Maria Teresa Tedesco Vilardo Abreu (2016) postula:

A linguagem é um mecanismo que faz parte da natureza do ser humano, que possui a necessidade natural de se agrupar em sociedade, a fim de realizar seus objetivos. Por isso, consciente de suas limitações, cada pessoa busca no outro a complementação de si mesmo. E o instrumento, o meio que permite essa aproximação entre pessoas, é justamente a linguagem, por favorecer o pensar e o agir. (ABREU, 2016, p. 14)

Comunicar-se é uma prática essencial à existência humana, sobretudo a partir das transformações que a popularização da internet tem provocado. Tal fato exige que o sujeito seja capaz de lidar com textos de variados tipos e gêneros, o que se configura como uma habilidade a ser desenvolvida no decorrer de toda sua trajetória educativa e não apenas nas séries iniciais. Freire destaca:

\footnotetext{
O problema que se coloca não é o da leitura da palavra mas o de uma leitura mais rigorosa do mundo, que sempre precede a leitura da palavra. Se antes raramente os grupos populares eram estimulados a escrever seus textos, agora é fundamental fazê-lo, desde o começo mesmo da alfabetização para que, na pós-alfabetização, se vá tentando a formação do que poderá vir a ser uma pequena biblioteca popular, com inclusão de páginas escritas pelos próprios educandos. (FREIRE, 2009, p. 19)
}

Nesse contexto, considera-se o desenvolvimento das habilidades da leitura e da escrita como a base da formação humana. Trata-se da porta de acesso ao conhecimento, à construção e à criação de ideias, de valores e de ideologias. A linguagem é o elemento-chave para se ter acesso às diversas ciências e é, sobretudo, a matriz da educação, uma vez que "saber ler e escrever, já entre os gregos e romanos, significava as bases de uma educação adequada para a vida" (MARTINS, 1994, p. 22). 
A escrita é capaz de provocar modificações de diferentes tipos, sejam sociais, culturais, econômicas ou linguísticas, cujo aprimoramento possibilita ao sujeito passar a fazer parte de outros grupos sociais. Então, apropriar-se da escrita implicaria a inserção do indivíduo na sociedade e significaria que ele a usa e a domina em seus diferentes níveis, desde um simples bilhete até um texto científico.

Nos últimos trinta anos, uma tempestade de novos gêneros invadiu e revolucionou a relação humana com a escrita, reflexo incontestável das demandas produzidas pelas inovações tecnológicas emergentes no mundo. Tais mudanças, evidentemente, provocaram transformações políticas, sociais, econômicas e, especialmente, linguísticas, afetando, também, o processo de ensino e aprendizagem.

Por conta dessas circunstâncias, tem sido bastante desafiador adaptar os currículos escolares para atender a tais demandas. Os Parâmetros Curriculares Nacionais (PCNs), publicados em 1998, e, mais recentemente, a Base Nacional Comum Curricular (BNCC), em 2018, são diretrizes, de âmbito nacional, desenvolvidas com o objetivo de nortear as práticas pedagógicas em sala de aula:

O objeto de ensino e, portanto, de aprendizagem é o conhecimento linguístico e discursivo com o qual o sujeito opera ao participar das práticas sociais mediadas pela linguagem. Organizar situações de aprendizado, nessa perspectiva, supõe: planejar situações de interação nas quais esses conhecimentos sejam construídos e/ou tematizados; organizar atividades que procurem recriar na sala de aula situações enunciativas de outros espaços que não o escolar, considerando-se sua especificidade e a inevitável transposição didática que o conteúdo sofrerá; saber que a escola é um espaço de interação social onde práticas sociais de linguagem acontecem e se circunstanciam, assumindo características bastante específicas em função de sua finalidade: o ensino. (BRASIL, 1998, p. 22)

\section{O componente Língua Portuguesa da BNCC dialoga}

com documentos e orientações curriculares produzidos nas últimas décadas, buscando atualizá-los em relação às pesquisas recentes da área e às transformações das práticas de linguagem ocorridas neste século, devidas em grande parte ao desenvolvimento das tecnologias digitais da informação e comunicação (TDIC). (BRASIL, 2018, p. 63)

Tal seleção de conteúdos permite certa flexibilidade para se adequar as propostas pedagógicas ao perfil de cada grupo, considerando a região, a cultura, a faixa etária e outros fatores que fazem parte da formação do sujeito, além de ilustrar a difícil tarefa de escolha de determinado item em detrimento de outro. 
Desse modo, para realizar a estruturação do ensino de Língua Portuguesa é preciso proceder à escolha de temas e conteúdos diversificados, visto que o ensino de Língua Portuguesa pretende capacitar o indivíduo para que ele possa transitar pelas diferentes funções da escrita: uso social (receitas, anotações, mensagens), uso utilitário (listas de compras, receitas, bulas, atlas, notícias), uso emotivo (diários, blogs, declarações de sentimentos) ou para o lazer (histórias em quadrinhos, novelas, romances, poesia).

Por isso, cabe ressaltar que:

o currículo é o oferecimento de conhecimento, habilidades e atitudes socialmente valorizados e postos à disposição dos estudantes, através de uma variedade de arranjos, durante o tempo em que eles estão na escola, na faculdade ou na universidade (KELLY, 1981).

Sendo assim, pode-se inferir que os estudos da Língua Portuguesa devem partir da análise de textos, enfatizando os aspectos lexicais, a ampliação do vocabulário do repertório cultural, de maneira a estimular o uso da linguagem nas suas múltiplas finalidades.

Marcuschi ressalta:

já se pode indagar se a escola deverá amanhã ocupar-se de como se produz um e-mail e outros gêneros do discurso 'eletrônico' ou pode a escola tranquilamente continuar analisando como se escrevem cartas pessoais, bilhetes e como se produz uma conversação (MARCUSCHI, 2010, p. 19).

É válido atentar-se para uma das reflexões de Martins (1994, p. 23) que enfatiza a natureza e os níveis de leitura, uma vez que se pode ler com o objetivo de entreter, de informar e/ou de formar. Nessas três naturezas da leitura, não se está isento do envolvimento com o texto, de se manter uma relação dialógica com ele. Em todas elas, a leitura implica o rompimento da passividade do leitor e o enfrentamento de uma situação, mas, para isso, ele deve sair do estado de decodificador das palavras e reconstruir novos conhecimentos, o que está na base das demandas sociais e da escrita.

O ensino de Língua Portuguesa configura-se como difusor da leitura e como catalisador da escrita, já que tem por objeto o texto e, a partir dele, objetiva-se desenvolver o leitor/escritor autônomo, capaz de compreender diversos gêneros textuais e articular ideias a fim de melhorar a sua prática social, como previsto nos documentos norteadores.

Gêneros textuais nascem e renascem, disputando espaços, sendo utilizados a todo momento, mesmo sem a autorização dos seus leitores. Ainda há aqueles mais 
tímidos, que se mostram apenas àqueles que lhes procuram, de acordo com sua realidade ou área de interesse. O mais relevante dessas reflexões é o desenvolvimento das competências linguísticas que propiciem ao indivíduo transitar por diferentes gêneros, por diversas esferas da comunicação, pois é esta a ferramenta da capacidade humana propícia a revolucionar qualquer época.

\title{
TECNOLOGIA E EDUCAÇÃO
}

Não há como dissociar a internet do uso da língua escrita, visto que, em algumas situações comunicativas, a escrita vem ocupando espaços sociais que até então eram exclusivos da oralidade. Sobre esta comunhão, a Base Nacional Curricular Comum destaca os impactos da cultura digital, sobretudo nos adolescentes:

\begin{abstract}
Há que se considerar, ainda, que a cultura digital tem promovido mudanças sociais significativas nas sociedades contemporâneas. Em decorrência do avanço e da multiplicação das tecnologias de informação e comunicação e do crescente acesso a elas pela maior disponibilidade de computadores, telefones celulares, tablets e afins, os estudantes estão dinamicamente inseridos nessa cultura, não somente como consumidores. Os jovens têm se engajado cada vez mais como protagonistas da cultura digital, envolvendo-se diretamente em novas formas de interação multimidiática e multimodal e de atuação social em rede, que se realizam de modo cada vez mais ágil. Por sua vez, essa cultura também apresenta forte apelo emocional e induz ao imediatismo de respostas e à efemeridade das informações, privilegiando análises superficiais e o uso de imagens e formas de expressão mais sintéticas, diferentes dos modos de dizer e argumentar característicos da vida escolar. (BRASIL, 2018, p. 57)
\end{abstract}

É também no ciberespaço que a comunicação e as relações sociais têm lugar: um local em que a comunicação independe da presença física do homem, permitindo que a capacidade humana de armazenamento e processamento de informação seja melhor explorada, conforme relata Edméa Santos (2017):

\footnotetext{
O ciberespaço se constitui e é constituído pelas tecnologias digitais em rede, que é para nosso tempo um dos mais importantes artefatos técnico-culturais, pois ampliam e potencializam a nossa capacidade de memória, armazenamento, processamento de informações e conhecimentos, e, sobretudo, de comunicação. (SANTOS, 2017, p. 77)
}

"Um dos aspectos essenciais da mídia virtual é a centralidade da escrita, pois a tecnologia digital depende totalmente da escrita” (MARCUSCHI, 2010, p. 21). É coerente inferir, portanto, que a democratização do acesso à internet tem obrigado as pessoas a usarem a escrita com maior frequência, uma modalidade de expressão que 
sempre foi tão temida pela maioria pouco escolarizada e, ao mesmo tempo, idolatrada pelos eruditos da língua. A língua escrita ganhou evidência e vem conquistando cada vez mais espaço e prestígio social.

Com características e estrutura próprias, os processos comunicativos que ocorrem na internet, especialmente nas redes sociais ou em aplicativos de bate-papo, revelam uma comunicação viva, própria da oralidade, elaborada de forma complexa na qual a leitura e a escrita assumem características específicas. É o caso de gêneros textuais como o e-mail, o chat, o bate-papo, o blog ou vídeo. Citando Thomas Erickson, Marcuschi destaca (2010):

\begin{abstract}
interação on-line tem o potencial de acelerar enormemente a evolução dos gêneros, tendo em vista a natureza do meio tecnológico em que ela se insere e os modos como se desenvolve. Esse meio propicia, ao contrário do que se imaginava, uma "interação altamente participativa", o que nos obrigará a rever algumas noções já consagradas. (MARCUSCHI, 2010, p. 20)
\end{abstract}

A videoconferência interativa (no contexto educacional), por exemplo, é um gênero popularizado recentemente. Este recurso aproxima-se dos bate-papos com convidados, mas tem tema fixo e tempo claro de realização com parceiros definidos. As videoconferências são síncronas e essencialmente institucionais com fins profissionais ou educacionais e ainda dependem de uma tecnologia mais sofisticada. Como se pode observar nos casos nos quais se faz uso deste novo gênero, a escrita é usada em menor intensidade e elas se aproximam dos telefonemas com imagem em circuito fechado (MASCUSCHI, 2010, p. 69).

Pode-se dizer que as videoconferências são as precursoras das lives: apresentação de conteúdo de entretenimento, acadêmico, informativo, educacional ou para qualquer outro fim, através de transmissão ao vivo, exibidas em redes sociais. Elas tornaram-se um dos recursos adotados para aulas na modalidade remota ou em ensino a distância.

Mesmo antes da pandemia, lentamente, as plataformas EAD vinham conquistando espaço e aceitação do público em geral. São cursos de diversos níveis oferecidos em ambiente como uma sala de aula, cujos conteúdos são apresentados nas formas síncronas ou assíncronas, ministrados por tutores ou instrutores que adotam estratégias de interação como debates, fóruns, questionários, leituras, reprodução ou produção de vídeos ou de arquivos de áudio (podcasts). 
Além disso, a possibilidade de compartilhar conhecimento sem hora marcada permite flexibilidade ao educador que pode preparar previamente as publicações e, aos alunos, que podem acessar o conteúdo nos horários que lhes forem mais convenientes. No entanto, é preciso cautela, visto que todos acabam ficando sujeitos a um permanente estado de conexão on-line, o que pode trazer consequências negativas para o trabalho e para a saúde mental.

Acerca da modalidade de ensino a distância, esclarece Elvia Nunes Ribeiro (2007):

De acordo com a Secretaria de Educação a Distância, a diferença básica entre educação presencial e a distância é que na EAD o aluno tem acesso ao conhecimento e desenvolve hábitos, habilidades e atitudes relativos ao estudo, à profissão e à sua própria vida, no tempo e local que lhe são adequados, não com a ajuda em tempo integral da aula de um professor, mas com a mediação de professores (orientadores ou tutores), atuando ora a distância, ora em presença e com o apoio de materiais didáticos sistematicamente organizados, apresentados em diferentes suportes de informação, utilizados isoladamente ou combinados, através dos diversos meios de comunicação. (RIBEIRO, 2007, p. 4)

Tendo em vista a situação imposta pela pandemia, as redes sociais atuaram como plataformas EAD. Em geral, elas dispõem de muitos meios de interação entre seus usuários, como a publicação de mensagens, fotos ou vídeos, criação e divulgação de páginas, grupos, eventos. Contudo, a dispersão provocada pelas inúmeras distrações comuns ao espaço virtual pode comprometer o resultado almejado, problema incomum em plataformas específicas para ensino a distância.

\section{ESTRATÉGIAS DIDÁTICAS DA SECRETARIA MUNICIPAL DE EDUCAÇÃO DO RIO DE JANEIRO}

A Secretaria Municipal de Educação (SME-RJ) é um órgão da Prefeitura Municipal do Rio de Janeiro que, de acordo com as informações em seu portal público (SECRETARIA MUNICIPAL DE EDUCAÇÃO, 2020), administrou, em 2020, 1.542 unidades escolares localizadas na capital carioca. Destas, 990 unidades atenderam a alunos do ensino fundamental, e 535 unidades a alunos de Educação Infantil (EDI). As demais unidades atendem alunos de Educação Especial, de Educação de Jovens e 
Adultos (EJA) ou são unidades olímpicas. Tal rede de ensino, em 2020, contava com 39.597 professores que lecionaram para 641.141 alunos matriculados.

A SME-RJ disponibiliza um portal acessível a qualquer usuário, inclusive para alunos e responsáveis. Nele são encontradas informações a respeito da educação na rede municipal, desde o calendário escolar até materiais de apoio pedagógico.

Desde 2016 a SME-RJ produz material didático impresso que é enviado para as escolas periodicamente, propondo atividades didáticas para aplicação dos conteúdos das disciplinas de Língua Portuguesa, Matemática e Ciências. De acordo com a Secretaria, as atividades são planejadas por uma equipe de professores da rede que se inscrevem em processo seletivo interno especificamente para realização desse trabalho.

No que se refere às propostas pedagógicas de Língua Portuguesa, o currículo tem por objeto de estudo o texto e considera a linguagem sob sua perspectiva social:

\begin{abstract}
Na concepção que compreende a língua/linguagem como um fenômeno social. $\mathrm{O}$ ensino fundado nessa concepção significa uma escolha por trazer para o centro da aula a língua portuguesa como se apresenta na vida: múltipla, variável, dinâmica e inserida no jogo social. Dessa forma, ganham centralidade as atividades que possibilitam ao aluno o contato com a língua portuguesa em uso. A atitude diante do fato linguístico passa necessariamente pela relação uso-reflexão-uso. (SME, 2020, p. 2)
\end{abstract}

Para estruturar e alinhar as habilidades, o currículo apoia-se em quatro eixos/pilares, oralidade, leitura, escrita e análise linguística, os quais foram reorganizados da seguinte forma: oralidade e análise linguística; leitura e análise linguística; escrita e análise linguística.

Por conta da pandemia e da necessidade da implantação do ensino remoto, a SME-RJ lançou um aplicativo com conteúdo pedagógico para os estudantes de todas as etapas educacionais, disponível na plataforma da Multirio (2020). Ademais, muitas escolas adotaram estratégias de ensino utilizando as principais redes sociais.

No aplicativo ou no portal, é possível acessar o Material de Complementação Escolar (MCE), cuja proposta principal é contribuir com a aprendizagem de cada disciplina, em casa, durante o período de distanciamento social. Publicado semanalmente, além de propor atividades que visam a reforçar o conteúdo previsto para cada etapa/série, há indicação de consultas a vídeos e outros materiais de domínio público. 
Analisando o seu conteúdo curricular, pôde-se perceber que o ensino de Língua Portuguesa é proposto a partir de textos verbais e não verbais e, frequentemente, há uma relação dialógica entre eles. Pretende-se explorar a construção de sentido, a leitura do implícito, do explícito, a produção da escrita e da reescrita.

Conforme apresentado anteriormente, o MCE propõe o ensino de língua materna pautado nos três pilares, oralidade, leitura e escrita, relacionando-os à análise linguística, a partir dos gêneros textuais, com o objetivo de:

\begin{abstract}
levar os alunos a produzirem ou analisarem eventos linguísticos os mais diversos, tanto escritos como orais, e identificarem as características de gênero em cada um. É um exercício que, além de instrutivo, também permite praticar a produção textual (MARCUSCHI, 2002).
\end{abstract}

Há, ainda, grande predominância de gêneros textuais que adotam a imagem como ferramenta discursiva, como a própria história em quadrinhos, anúncios publicitários, cartazes, charges ou cartuns. Estes, sem dúvida, são gêneros presentes na prática social dos alunos, sobretudo porque são textos cuja leitura aciona o conhecimento de elementos não verbais (cores, imagens, figuras etc.) e atraem o interesse do leitor.

O referido material publica o gabarito das atividades propostas, mas não prevê recursos de interação entre professores e alunos. Isto é, o professor não interfere no processo ensino-aprendizagem. Também não são previstas avaliações da eficácia do ensino remoto nas condições em que foi implementado.

\title{
RESULTADOS
}

Cada vez mais, é possível perceber os efeitos ocasionados por uma sociedade virtualmente organizada: relações pessoais são substituídas por contatos virtuais, novelas são substituídas por histórias reais expostas na rede, salas de aulas expandem-se para os ambientes virtuais. O conhecimento espalha-se de maneira surpreendente, ainda mais na situação da crise sanitária mundial provocada pelo coronavírus, que impulsionou um extraordinário espaço de trocas, de compartilhamentos, de construções coletivas, ampliando as oportunidades e as possibilidades para exposição do pensamento. 
Apesar dessa nova modalidade parecer ser muito vantajosa para as relações humanas, a situação exigiu que todos colocassem em prática (ou desenvolvessem) habilidades para uso das tecnologias no contexto digital. À vista disso, aprimorar a linguagem fez-se uma necessidade primordial e, ainda que pareça o oposto, a comunicação virtual, baseada na fonética (assim como a norma culta da língua), apresenta regras e busca integrar as modalidades oral e escrita. Apesar da predominância do uso da escrita, a web é o espaço onde a integração entre ambas as modalidades flui involuntariamente, propiciando a criação de novos modelos, adequando as regras, adotando novos recursos.

No que tange ao Material de Complementação Escolar de Língua Portuguesa utilizado nesta pesquisa, embora apresente estratégias e metodologias que integram o uso das mídias à prática educativa, não foge ao tradicional esquema de perguntas e respostas sobre determinado assunto. Há poucas provocações no sentido de estimular a leitura e a produção de textos do cotidiano que contribuam para a construção da autonomia intelectual dos alunos.

Também há pouca ocorrência de produção e leitura de textos de discurso tecnológico (bate-papo, comentários, vídeos), uma vez que a ideologia uso-reflexão-uso diante do fato linguístico está limitada ao contexto físico.

No que tange aos conteúdos de Língua Portuguesa, o material elaborado pela SME-RJ, apresenta as seguintes observações:

a) O ensino de Língua Portuguesa pauta-se nas propostas pedagógicas que partem do estudo da língua a partir de textos, como defendem alguns autores de renome dos estudos linguísticos;

b) A seleção dos textos ocorre a partir da determinação dos tipos textuais que são apresentados ou discutidos. Há predominância da relação entre textos verbais e textos imagéticos;

c) O trabalho pretende pautar-se nos quatro pilares: oralidade, leitura, escrita e análise linguística. Para esta última, o enfoque é dado através de expressões ou frases retiradas do texto base que propõem reflexões sobre o funcionamento das formas linguísticas na coesão do texto, de forma bastante superficial. A leitura é o eixo que recebe maior destaque nas propostas apresentadas. 
d) $\mathrm{O}$ aprofundamento nos temas propostos é sugerido a partir de pesquisas em redes sociais ou em sites de pesquisas dos conteúdos bases. Há proposições de pesquisas na web como forma de aprofundamento do saber apresentado no material, bem como sugestões de filmes ou vídeos ligados ao tema.

Diferente do ensino remoto, a modalidade ensino a distância oferece uma plataforma adequada, propícia, pensada para que o aprendizado, de fato, aconteça. São planejadas todas as etapas da aprendizagem, inclusive a avaliação. Também é prevista a interação entre professor ou tutor e aprendiz, fundamental ao processo de aprendizagem.

No entanto, o trabalho proposto pelo MCE não prevê a interferência do professor na aprendizagem. O ensino remoto não foi antevisto, muito menos planejado, e surgiu como uma proposta emergencial para amenizar os impactos da impossibilidade de se estar em sala de aula fisicamente. É uma solução temporária a fim de cumprir o calendário escolar. $\mathrm{O}$ ambiente virtual apresentado é pouco adequado, pois inviabiliza as interações entre aluno-professor-alunos e é generalista, ao passo que não pressupõe as adaptações necessárias segundo a identidade de cada unidade escolar, de cada turma, de cada aluno.

\section{CONSIDERAÇÕES FINAIS}

Os impactos dos efeitos da pandemia provocada pelo coronavírus serão percebidos a longo prazo. A necessidade de manter o distanciamento social como estratégia de prevenção à doença provocou transformações nos diversos níveis: pessoal, familiar, social, tecnológico e, também, educacional.

Neste último, os desafios que esta nova era social e tecnológica impôs aos docentes foi, preliminarmente, conhecer e transpor sua prática pedagógica a plataformas que tentam se aproximar do contexto escolar presencial. Foi um período com forte demanda por recursos e conhecimentos que oferecessem estratégias de trabalho utilizando ferramentas midiáticas que pudessem ser incorporadas ao cotidiano escolar.

Para fazer uso de tais recursos foi fundamental que se tivesse o mínimo de conhecimento das habilidades necessárias para utilizar a mídia adotada como ferramenta desse processo de aprendizagem. Ainda que o indivíduo, aluno ou professor, tenha, inicialmente, encontrado dificuldades, foi preciso um conhecimento básico capaz de 
possibilitar a interação em diferentes interfaces: gravar um vídeo, postar em redes ou plataformas, converter textos em imagens.

Um ponto facilitador dessa situação é que o alunado, a geração do século XXI, tem apresentado muita facilidade em aprender e operacionalizar diversas mídias, o que se configura como uma grande vantagem para aqueles que precisavam aliar o ensino ao uso de tecnologias. A interação social, a criação de perfis personalizados, a manipulação de conteúdos, a participação em grupos e comunidades são algumas das habilidades que os adolescentes e os jovens realizam com certa facilidade.

Como tais habilidades foram desenvolvidas é uma questão intrigante. Notam-se poucas práticas relacionadas ao estímulo à leitura e à produção de textos do discurso tecnológico (e-mail, posts, blog, videolog, comentários, entre outros), deixando a aprendizagem de leitura e a produção destes gêneros ao acaso. São poucas as estratégias de ensino de língua materna que preveem e integram a relação entre o contexto físico e o contexto digital, conhecimento fundamental para o sucesso da aprendizagem durante o ensino remoto.

As práticas pedagógicas antes da pandemia não previam o desenvolvimento da autonomia do alunado em função do uso de mídias tecnológicas e, se assim o fosse, certamente as dificuldades seriam menores.

Então, é imprescindível atualizar o currículo escolar, contextualizando-o ao ambiente digital, demandas exigidas pela sociedade contemporânea. As redes sociais apresentam diversos recursos que podem ser utilizados como ferramenta de apoio pedagógico e, devido à facilidade no acesso, graças a elas foram vislumbradas oportunidades para a propagação do conhecimento.

A primeira grande vantagem dessa proposta é o fato de que amplia a aprendizagem para além dos limites físicos e cronológicos da escola, alcança o ciberespaço, permitindo que o indivíduo module a seu tempo a construção do conhecimento. Além disso, é também um espaço que favorece o desenvolvimento da autonomia, fortalece as relações pessoais, multiplica a troca de informações, aproxima ideias afins e possibilita discussões de ideias diversas.

As redes sociais serviram como ferramenta propícia ao auxiliar no processo de ensino-aprendizagem da Língua Portuguesa em educação remota, sobretudo por 
constituírem um espaço virtual popular e relativamente acessível ao público, o que dispensou a etapa de ambientação, de familiarização com o seu manuseio.

Através das redes sociais, as lives multiplicaram-se e ampliaram o alcance de apresentações com fins acadêmicos e educacionais de tal forma que se tornou difícil conceber a sua terminalidade. Até então, eventos acadêmicos e outras situações especificamente pensadas para compartilhar conhecimentos estavam restritas ao espaço físico.

Os limites da educação remota não estão restritos ao planejamento curricular. O acesso à educação escolar ficou disponível àqueles que dispunham de tecnologias, de acesso à internet, de habilidade para se comunicar nesse contexto, de aptidões físicas e mentais para se adaptar aos novos métodos. Além disso, a peça fundamental ao aprendizado se instaurou de forma muito cerceada: o professor.

Eis os limites do ensino remoto: o aprendizado não é uma exposição simples e fria de conteúdos (principalmente nos níveis iniciais da educação escolar) e é o professor quem transforma essa realidade. É ele o elemento que planeja todas as etapas do aprendizado, que tem a percepção capaz de conduzir ao saber, que modifica o percurso sempre que percebe necessidade, que estuda, aprende e desenvolve em si a capacidade de ensinar.

Por isso, as expectativas relacionadas aos resultados no aprendizado não são positivas. A desigualdade social, um problema que afeta grande parte do país, vai refletir no processo educacional, uma vez que o aporte necessário para acesso à internet demanda recursos financeiros que boa parte da população não dispõe para arcar com tal despesa.

Isto posto, inserir no cotidiano escolar o uso de meios midiáticos, contextualizar a prática pedagógica com a realidade contemporânea, usar e abusar dos recursos que as redes sociais possibilitam são aspectos que devem ser considerados após o fim da pandemia. Para tanto, além das transformações que devem ser realizadas no âmbito educacional, vale destacar também a necessidade de que sejam promovidos investimentos políticos e sociais que favoreçam a inserção digital. É importante facilitar o acesso à internet e a equipamentos tecnológicos que permitam a expansão do aprendizado para espaços atualmente restritos a determinadas classes sociais. 
Um fato é indiscutível: ocorreram transformações no perfil do alunado e o processo educativo não pode se omitir de estar atento às demandas políticas e sociais necessárias para suprir e comportar as novidades e desafios da educação na atualidade. É preciso pensar o ensino de Língua Portuguesa com foco na capacidade de interagir com sucesso nas diversas práticas sociais de linguagem, nas competências que permitem usar de forma adequada as variedades da língua conforme a situação, seja ela física ou virtual.

\section{Referências}

ABREU, Maria Teresa Tedesco Vilardo. O ensino da produção escrita e as práticas de letramento. Revista Linguagens \& AMP, Campina Grande, v.1, n.1, p. 08-26, 2016. Disponível em: revistas.ufcg.edu.br/cfp/index.php/linguagensletramentos/article/view/6. Acesso em: 23 jun. 2020.

BRASIL. Ministério da Educação. Base Nacional Comum Curricular-BNCC. 2. ed. Brasília, 2018.

BRASIL. Ministério da Educação. Parâmetros Curriculares Nacionais: $3^{\circ}$ e $4^{o}$ ciclos do Ensino Fundamental: Língua Portuguesa. Brasília, 1998.

FREIRE, Paulo. A importância do ato de ler em três artigos que se completam. 50. ed. São Paulo: Cortez, 2009.

KELLY, Albert Victor. O currículo. Teoria e Prática. São Paulo: Harbra, 1981. Disponível em http://www3.uma.pt/jesussousa/DocumentosCCPCCDoutoramentoBrasil_ficheiros/3De finircurriculo.pdf . Acesso em: 01 ago. 2020.

MARCUSCHI, Luiz Antônio. Gêneros Textuais Emergentes no Contexto da Tecnologia Digital. Texto da Conferência pronunciada na 50a Reunião do GEL - Grupo de Estudos Linguísticos do Estado de São Paulo. São Paulo: USP, 2002.

MARCUSCHI, Luiz Antônio. \& Xavier, Antônio Carlos (orgs.). Hipertexto e gêneros digitais: novas formas de construção do sentido. 3. ed. Rio de Janeiro: Lucerna, 2010.

MARTINS, Maria Helena. O que é Leitura. 19. ed. São Paulo: Brasiliense, 1994.

SECRETARIA MUNICIPAL DE EDUCAÇÃO. Recursos Pedagógicos. Disponível em https://www.rio.rj.gov.br/web/rioeduca/recursos-pedagogicos. Acesso em: 22 ago. 2020. 
SECRETARIA MUNICIPAL DE EDUCAÇÃO. Currículo de Língua Portuguesa 2020. Disponível em http://www.rio.rj.gov.br/dlstatic/10112/10884556/4269410/LINGUAPORTUGUESA.p df. Acesso em: 01 ago. 2020.

SECRETARIA MUNICIPAL DE EDUCAÇÃO. Material de Complementação Escolar. Disponível em http://multirio.rio.rj.gov.br/index.php/estude/material-decomplementacao-escolar. Acesso em: 01 ago. 2020.

SECRETARIA MUNICIPAL DE EDUCAÇÃO. Educação em números. http://www.rio.rj.gov.br/web/sme/educacao-em-numeros. Acesso em: 01 ago. 2020

RIBEIRO, Elvia Nunes. et al. A importância dos ambientes virtuais de aprendizagem na busca de novos domínios da EAD. Goiânia: CEFET, 2007. Disponível em http://www.abed.org.br/congresso2007/tc/4162007104526AM.pdf . Acesso em: 03 jun. 2020.

SANTOS, Edméa. A Cibercultura e a educação em tempos de mobilidade e redes sociais: conversando com os cotidianos. 2017. Disponível em: https://pt.slideshare.net/edmea/cibercultura-e-educao-em-tempos-de-mobilidadeconversando-com-os-cotidianos. Acesso em: 15 abr. 2019. 